tage derived from suturing the abdominal wound in layers is so apparent that I find its adoption is becoming more and more common. I have thus sutured since my first advocacy of buried animal sutures quite twenty-five years ago, and for fifteen years with no other dressing than the collodion seal. Subse. quent hernia does not occur, and in over eight hundred laparotomies I recall but one case of subsequent hernia, and this in a case where the abdominal wall had become excessively thin from a large fibroid tumor.

A final question for consideration is the ever recurrent one: When shall we operate? As in ovarian cystoma, so here the pendulum of opinion constantly varies. Without doubt the larger number of abdominal surgeons are operating on cases today, which they would have judged ill-advised four years ago. In young women, small growths which cause pain, excessive menstruation and interfere with the func. tions of the pelvic organs should be no longer subject to unsatisfactory medication, since operation in these cases gives the lowest rate of mortality, and not seldom by a myomectomy results in complete restoration of unmutilated organs with restored functions. There is a general consensus of opinion that the patient will profit less by the cessation of the menopause than was earlier believed.

Many of the more dangerous growths develop comparatively late in life, a considerable percentage of which go on to most extraordinary development regardless of menstruation. When the patient is still within the cycle of menstrual life and the ovaries comparatively healthy, it is probably wiser not to remove them. It is my own belief that in the future a wise conservatism will give an approval for operative measures upon a very considerable class of invalids, now usually permitted to drag out a more or less wretched life of suffering. I would, however, urge the limitation of the operation to the practice of men who have equipped themselves in a special manner for this class of surgery, since it is not alone theoretic knowledge that he must master, but more especially a technic that shall make him at once an artisan and an artist.

BIBLIOGRAPHY.

1. Kimball, Gilman: Successful Case of Extirpation of the Uterus, Boston Med. and Surg. Jour., May 3, 1855, Vol. liii, p. 249

2. Storer, H. R.: Suprapubic Hysterectomy for Fibroids, Sept. 23, 1865. Amer. Jour. of Med. Science, June, 1866.

Clay, Charles: A Successful Case of Entire Removal of the Uteru and its Appendages, Trans. London Obstet. Soc. 1863, Nol. v. p. 58 .

5. Marcy, fienry O.: Hysterectomy, Trans. Interaational Med. Cong., 1881. Vol. ii, pp. 233-234. Fibroid Tumors of the Uterus Trans. Cons. Med. Ass'n., Vol. xxxiii, pp. 175-208. Histology and Surgical Treatment of Uterine Myoma, President's Address, Secretary of Gynecology and Diseases of Women, Ninth International Med. Cong., 1887, Vol. ii, pp. $83 \overline{5}-84 \overline{5}$.

6. Stinson, I. E.: Ligation of the Uterine Arteries in their Continuity as an Early Step in Total or Partial Abdominal Hysterectomy, New York Med. Jour., March 9, 1889, Vol. xlix, p. 27 i

7. Baer, B. F.: Supravaginal Hysterectomy witiout Ligature of the Cervix in Operation for Uterine Fibroids, A New Method, Trans Amer. Gyn. Soc., 1892, Vol x xii, p. 235.

8. Eastman, Joseph: Work in Abdominal and Pelvic Surgery, Ind. Med. Jour., April, 1890, Vol, viii, p. 219 Total Extirpation der Gebär mutter Weren Myoma, Zeitschrift f. rationelle prak tische Aerzte, Jul 11, 1890, Vol. Xxxiv, Jahrang $i$, Heft, p. 389

Noble, Char Fi.: The Development and Present Status of Hysterxxii.

Storer, H. R.: Pocketing Pedicle, Jour. of Gyn. Soc. of Boston, Jol. i, p. 150 .

1, Jones, Mary A. Dixon: Two Cases of Uterine Myoma: one Supra Med. Jour., Aug. 25 and Sept. 1, 1888, Vol. xlviii, pp. 198 and 227 . 12. Kelly, Howard A. Hysterectomy by Continued Incision from Left February and Mareh, 1896, Vol. vii, Nos. 59 and $60,10.27$.

13. Allen, Dudley P.: Hysterectomy for Removal of Large Uterine Myomata by the Combined Vaginal and Abdominal Methods. Boston Med. and Surg. Jour., 1898, Vol. cxxxviii, No. 21, p. 48.

14. Battey, Robert: Oöphorectomy, Trans. International Med. Cong. 1881, Vol. it, pp. 279-288.

15. Baldwin, J. F.: The Technique of Abdominal Hysterectomy, Jour Amer. Med, Ase'n, Dec, 11, 1897, Vol. xxix, p. 1192.
THE INDICATIONS FOR PLASTIC SURGERY

UPON THE CERVIX UTERI, TRACHE-

LOPLASTY, WITH A NEW METHOD

OF OPERATING.

Presented to the Scction on Obstetrics and Diseases of Women, at the Forty-ninth Annual Meeting of the American Medical Association, held at Denver, Colo., June 7-10, 1898.

BY H. P. NEWMAN, A.M., M.D.

CHICAGO.

The operation known as trachelorrhaphy or Emmet's operation, has been in vogue for thirty-five years. It has had a brilliant history and has won honors for the originator wherever gynecology is practiced, but like many good things it is not only capable of improvement, but has of late been quite generally superseded by operations in the nature of amputation; plastic work looking toward removal of diseased tissue, restoration of organic function, and remodeling of the cervix to as nearly normal outlines as possible. These operations are commonly known as amputation of the cervix, but only for want of a better name, since it suggests the crudeness of the former excision of the neck of the uterus, and in no way conveys all that is comprehended in the newer work. There is a wave of interest abroad concerning these improved mothods, and many reports of admirable work are being made in foreign journals. In our own country. Emmet himself concedes that his original operation for pathologic conditions following laceration has had its day, and suggests for it honorable retirement to a few wellselected cases. On pages 351-2 of the $A m$. Gyn. and Obstet. Journal, Vol. ii, 1897, he says: "Since the writer's attention has been drawn more particularly to the subject of amputation of the cervix uteri as a necessary operation after laceration, he has realized that a very important change for the better has taken place within the past twenty years in the practice of obstetrics. As the custom has now become a general one to employ every antiseptic precaution in obstetric practice, when laceration of the cervix occurs the efforts of nature thus assisted are sufficient in all but the worst cases to fully repair a very large proportion of tears. The writer [Emmet] has also recognized the fact that within a few years past a comparatively smaller number of this lesion which need 'Emmet's operation' for repairing the cervix are now seen in practice. The condition has become directly reversed within a few years past, and now, with but few exceptions, amputation is the proper means to employ. 'Emmet's operation' fully filled its place under the then existing circumstances and still does so whenever indicated, but the author (Emmet) now offers through the publication of this paper, an equally original operation (amputation) for the relief of pathologio laceration of the cervix as it is now met with." Elsewhere in the same article under the title, "When to Amputate in Preference to Repair of a Lacerated Cervix by the Usual Method," Dr. Emmet says: "For many years I held the opinion that it was possible, in almost every instance, by careful local and general treatment to restore in time the lacerated tissues to so near the normal condition, that when the operation had been properly performed, complete restoration would eventually take place with the result of bringing about involution of the uterus. But I am now of the opinion that there are exceptional cases to this rule, where under certain conditions it is better surgery to ampuate a portion or the whole cervix, provided the dis- 
eased tissues are completely removed and the wound afterward treated in the manner I shall describe."

While agreeing with the gifted author as to the desirability of the amputating operation, I claim that that mode of procedure is most excellent which requires least preparatory and after treatment, and which exacts least in the way of time and patience from patient and physician. There is a reaction against the tedium of routine local treatment that bids fair almost to go too far and abrogate it altogether. It is a detriment to any patient to be subjected to prolonged topical treatment. It has the tendency to establish the habit of invalidism, and to fix the attention inward, which is not a healthy stimulus to recuperation. I have for some years sought to do operative work of such a character that as much as possible may be accomplished at one sitting, and the patient led to expect prompt recovery and encouraged to consider herself well and free from bondage to the gynecologic chair. My results have so far been satisfactory, and it is to call attention to a method of cervical operation which meets these requirements that I have selected this subject. My manner of operating differs materially from any so far described, and possesses certain advantages which I hope will commend them. selves in comparison with existing modes. As yet, there is no unity in choice of technique. Dr. Von Ramdohr said recently ( $A m$. Gyn. and ()bstet. Jour., page 711): "As long as there are twenty-five methods of doing things none of them is good." This has a measure of truth in it, but the progress of surgery is marked by the passing of modification after modification of good methods, and only in such a way can perfection be reached.

The poor results complained of by some good operators with amputating operations, I believe to be due to faulty technique. That is to say that following the older methods of Schroeder, Emmet, Pozzi and others so far described, does not attain what is desired, becanse these methods through inherent faults do not meet the indications. The following criticism is made by Dr. A. Palmer Dudley of New York." "In closing the wound one is very apt to narrow the canal to the extent of obstructing the escape of the normal discharges from the uterus, thereby injuring the woman instead of benefiting her. Many here can recall cases in which, before operating for laceration of the cervix, they could recognize no disease of the uterine appendages while afterward disease developed. Why? Simply because in repairing the cervix they closed it, prevented the normal discharge from the uterus, induced continual passive congestion of the endometrium, and the disease then traveled up the tubes."

Early in the history of the operation Pauly is said to have declared that: "Of all surgical operations the excision of the neck of the womb has hitherto been the most murderous."

Improvement in technique in many quarters has advanced the operation rapidly in favor, and it is due to the literature of gynecologic surgery that such progress should be duly reported. In giving a de. scription of my own method, I wish to touch upon the indications for which it is used, and to call attention to the development of opinion in this regard.

Dr. Thomas, in the fourth edition of his work on "Diseases of Woman," published more than two decades ago, gives as indications: "Malignant disease, great enlargement from cervical hyperplasia, longitu-

1 Tr. Gyn. Soc., Vol xx, page 30\%. dinal cervical hypertrophy, conical and projecting cervix and granular or cystic degeneration of intractable character." I have already spoken of the manner in which present authority sanctions its use in cases of laceration, and in addition we now consider chronic metritis and cervicitis, certain forms of displacement, what is known as congenital elongation or infantile uteri and stenosis as calling for such operations. Concerning the latter I find this comment in Gould:s Year Book for 1898, page ō34: "True cervical stenosis is a comparatively rare disease, it exists most often in the mind of the physician."

Notwithstanding this formidable comment upon a former paper of mine presented to this society, a large experience in the reality of the thing only confirms me in the opinion that cervical stenosis, whether of traumatic or congenital (?) origin, is yet a potent factor in the etiology of much pelvic pathology and an indication of radical error in the hygiene and growth of women.

What is known as congenital stenosis is rarely the result of embryonic divergence, but rather persistence of the infantile condition through lack of proper development at the developmental period.

In advocating amputation of the cervix for inflammatory conditions $L$. Touvenaint (France) says : "The curette, which gives excellent results in chronic corporeal endometritis, is altogether insufficient in cervical endometritis. The operation gives brilliant results preceded by curettage. We say 'preceded by curettage' because it is rarely the case that inflammation of the cervix has not been propogated to the cavity of the body, and the endometritis become general. It has certainly been established that amputation is the operation of choice." $\mathrm{He}_{\theta}$ further says: "Amputation of the cervix is not done solely for the sake of removing a part of the organ; it possesses also the advantages of inducing profound modification in the vitality of the entire uterus, so that this under. goes a veritable involution." Mundé, in an article on trachelorrhaphy in 1889, said: "When a superficial layer of an organ which is affected by hypertrophy is cut off, a marked tendency to diminution in the bulk of the remaining tissue shows itself." Curettage alone can not accomplish this result, although it can do much, and in connection with excision is a valuable adjunct. Not only the cervix, but its mucous lining differs from that of the uterus above in essential particulars, and chronic inflammation creates a dense, firm tissue with deep glandular involvement which only a sharp curette thoroughly used can remove. Such removal is apt to result in constriction of the canal amounting to a severe stenosis or even atresia unless followed by tedious and objectionable aftertreatment. As I have said, the ideal operation should attain restoration of physiologic as well as anatomic conditions, and with the smallest expenditure of time and the least possible manipulation.

The following are details of the method which I have found meet these requirements better than any of which I know. The patient, prepared as for any minor gynecologic or plastic surgery, is placed in the lithotomy (extreme dorsal) or Sim's position, and the cervix drawn down with the bullet forceps or the double tenaculum. The cervix is dilated and the uterus curetted in the usual manner. Curettage is used only when the indications for its employment exist, but these are so constant as to make it virtually the rule. The blades of the bullet-forceps are then 
reversed and replaced within the cervix so that their for ease in removal I am in the habit of treating them points are directed laterally from within outward. as follows: In tying the sutures one end of each is By using them in this manner traction is made upon left long, and these long ends are grouped by tying the inner area of the cervix leaving the anterior and them together according to their location. The three posterior walls free for making the flaps. The cervix anterior sutures form one group, the three posteriors is now transfixed by the knife here exhibited, (Fig. one group, and the two lateral sutures are tied 1a.) and a clean cut made from above downward, first together, a pair on each side, making four groups in in the posterior lip. (Fig. 1.)

The anterior lip is transfixed in a similar manner about $1 \mathrm{~cm}$. or $1 \frac{1}{2} \mathrm{~cm}$. in front of the other and cut in the same way.

The intervening plug of diseased tissue is now removed by a single cut or two of the curved scissors, the bullet-forceps having been changed to a lower position to allow of this. (Fig. 2.) If the flaps have been properly made they will now fall together, (Fig.

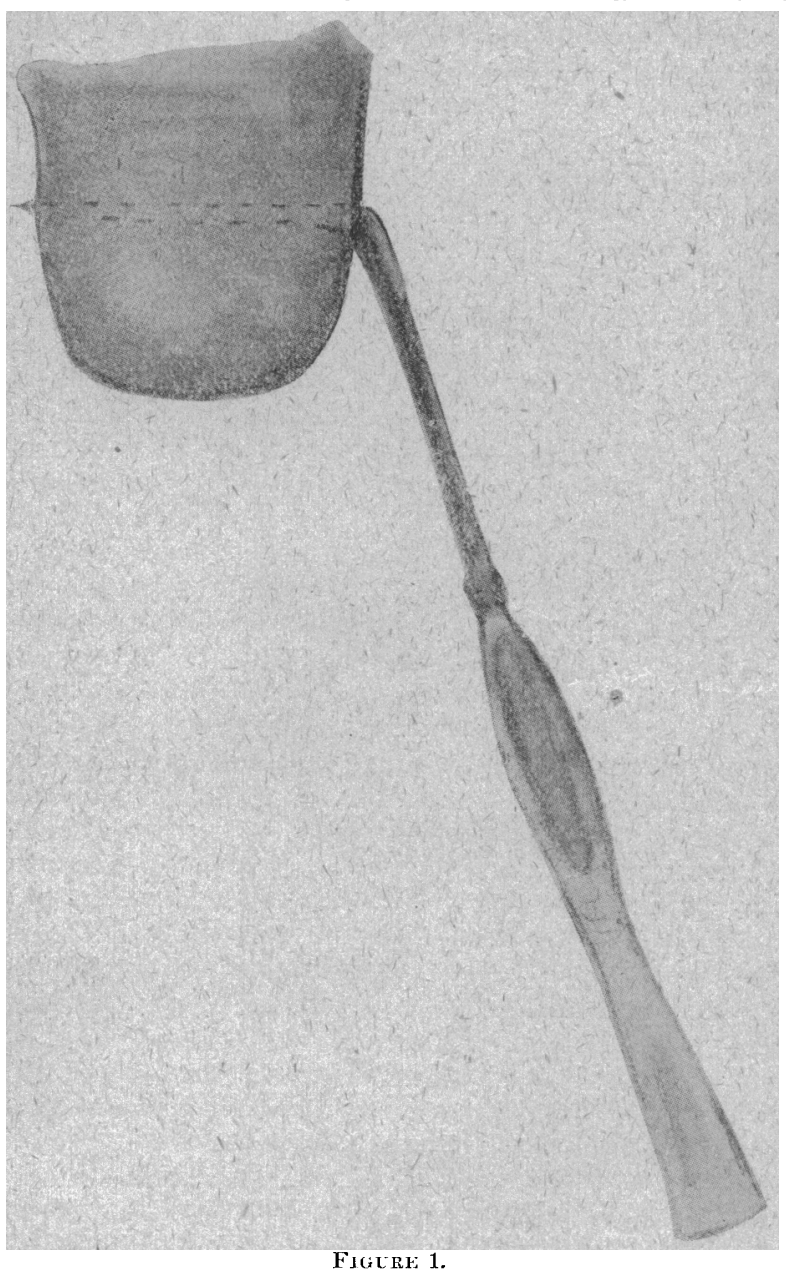

3) and inward, so as to assume the appearance of a normal cervix, and will require only the simplest suturing to keep them in this position. The first suture is passed through the center of the anterior flap a centimeter or more from its cut edge and brought out about three-fourths of a centimeter within the cervical canal. Two parallel stitches are now placed at each angle of the cervical canal. Silkworm gut is the suture material which I commonly use.

The posterior lip is similarly treated, except that it is somewhat easier in this situation to pass the sutures from within outward rather than the reverse, as in sewing the anterior lip. Two sutures are now passed, as in trachelorrhaphy, through the outer angles of the wound, which gap slightly after the turning in all. (Fig. 4 .)

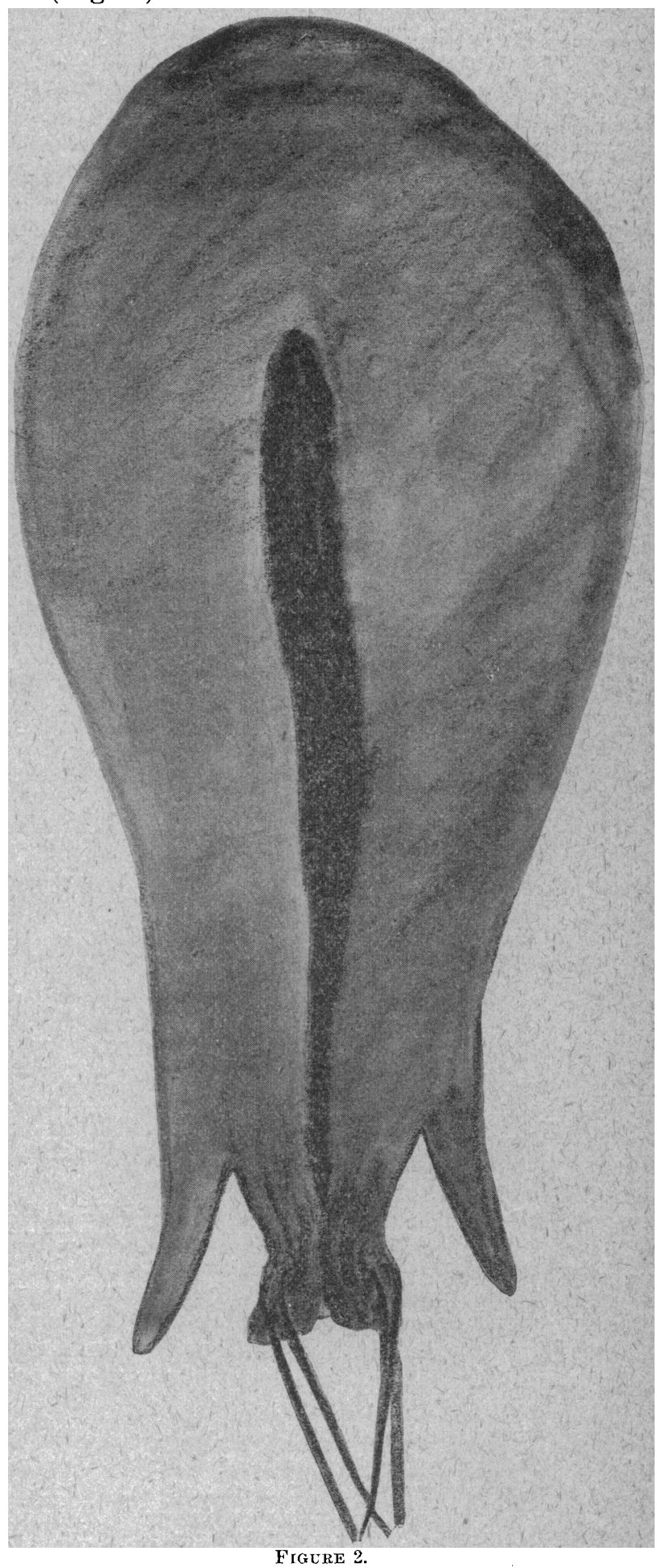

A uterine tampon of iodoform gauze or wicking is now inserted by means of this forceps and tamponcarrier. A projecting strand is attached to the vaginal tampon (also of gauze) in order that both of the flaps. For nice adjustment of the stitches and may be removed without undue disturbance of the 
parts. If no accessory work is done the usual perineal dressings are applied and the patient put to bed.

The external genitals are bathed with antiseptics after micturition but no douching of vagina or disturbance of tampons is allowed until the second or third day, when the entire tampon is removed and not replaced. Vaginal douches of 1-4000 bichlorid are then used twice daily. The sutures are removed at the end of two weeks, when the patient can be up.

The advantages claimed for this method of operating are: 1. The quickness and ease of operating by the knife here presented, the manner of making the flaps, transcending in certainty and safety of execution the ordinary methods of excision. 2. Clean, smooth-cut surfaces which are obtained without haggling of tissues, always most desirable in plastic surgery. 3. The easy approximation of flaps and the avoidance of all hemorrhage beneath them by deep placing of suture and compression of the flaps. 4. The accurate approximation of mucous membrane to

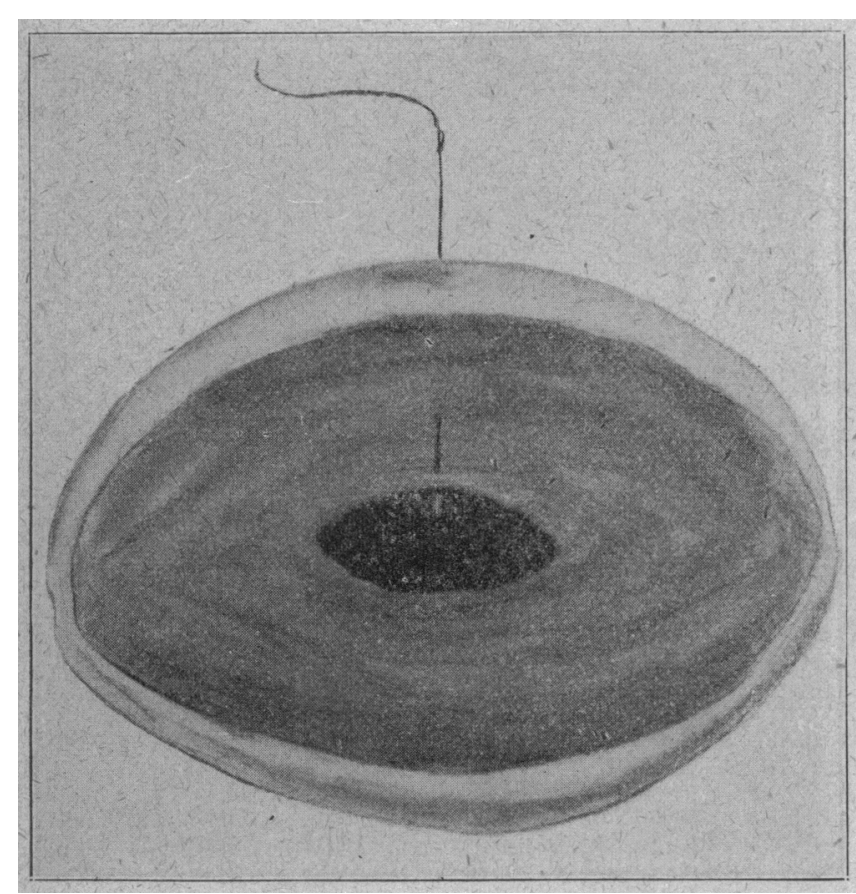

FigURE 3.

mucous membrane thus avoiding granulating surfaces, formation of cicatrix and constricting of the canal. This feature, which obtains also in Schroeder's operation and modifications of it, is of great importance and a decided advantage over trachelorrhaphy, especially where the entire cervical mucous membrane is removed. 5. The certainty of obtaining a permanently patulous canal and a well-formed cervix with pronounced reduction of the hyperplastic uterus. The simplicity of the after-treatment.

I would urge the necessity in doing plastic gynecologic work of fortifying it by doing all accessory operations at the same time. The neglect to do necessary complementary operations brings frequent failures. The operation I have described is seldom called for alone. While it will often correct a simple displacement of the uterus due to inflammatory conditions with increased size and weight, by correcting the lesion of the cervix and accompanying metritis and stimulating involution, it is not to be advocated as a substitute for the Alexander or other suspensio-uteri procedures. It will not restore the proper sustaining power of the pelvic floor, but it will be in many cases a valuable adjunct to any operation undertaken for these conditions. Dr. E. E. Montgomery says: "When a condition is due to lesions during the delivery of the patient, we have a large heavy uterus. In any case, in order to restore the patient to a normal condition the first aim should be to reduce the size of the organ. This is best accomplished by amputation of the cervix. The metabolic changes which take place as a result of the operation and the rest in bed will lead to a considerable reduction in size."

Besides correcting existing lesions and encouraging a return to the normal state it may be a determining factor in preventing the progress of malignant disease and the extension of infectious or infiammatory conditions to the adnexa. The cervix is an etiologic factor in many diseases; it is a storehouse for infectious

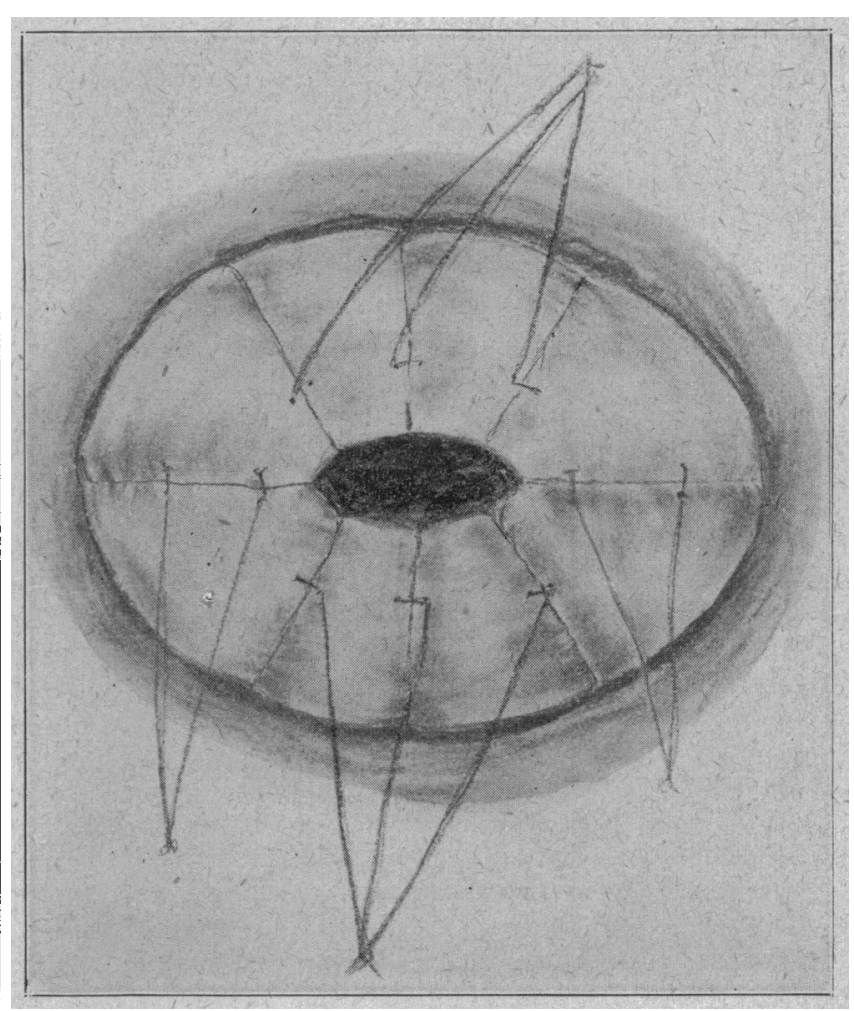

FIGURE 4,

germs; it is the portion of the uterus which suffers most from maldevelopment at puberty, thus causing dysmenorrhea, sterility and concomitant ovils; is most frequently injured in childbirth, so that until preventive medicine shall have succeeded in eradicating the more common causes of cervical diseases this organ will continue to offer wide opportunities for plastic surgery of the most careful and progressive kind.

In conclusion, I would offer a suggestion as to the nomenclature of the operation. Amputation of the cervix is as much too narrow a term for such work as trachelorrhaphy is too broad to be monopolized by the operation devised by Dr. Emmet. Much plastic work upon the cervix might be known as trachelor. rhaphy but since this name has been applied for so long to one class of methods exclusively, we are forced to find something more distinctly descriptive for the newer work. 
Amputation conveys the idea of taking away of an organ, whereas this work is really conservative, plastic surgery; nothing is removed but diseased or adventitious tissue, and I suggest that it be designated in future by the expressive and inclusive term Tracheloplasty.

LITERATURE.

L. Touvenaint: Rev. Internat de Méd. et de Chir. Paris, 1898, ix, 21.

A. Martin: Normandie Méd., Rouen, 1898, xili, 29

Del Vecchio: Rassegna d'ostet e gynec. Napoli, 1897, vi, 129.

R. Labusquiere: Ann. de gynec. et d'obst. Paris, 1897, xlvii, 318.

Pichevin. A. Emmet: Am. Obst.. Y. Y., 1897 ,

Pichevin. de med. de Paris, $1897,330$.

Tarmier: J. de sages-femmes, Paris, $1897, x \times v, 273$.

Audehert: Ann, de Gyn. et d'obst., Jan., 1898

Byrne: Transactions of the Am. Gyn. Soc. Vol, ii, page 57

E. E. I Trantgomery: Thera A Gaz $1895,726$.

A. P. Dudley: Trans. Am. Gyn. Soc. Vol. $x x$, page 305.

\section{ANTERIOR COLPOTOMY WITH REMOVAL OF ONE OVARY AND BOTH TUBES VAGINAL FIXATION.}

Presented to the Section on Obstectrics and Diseases of Women, at the Forty-ninth Annual meeting of the American Medical Association, held at Denver, Colo., June 7-10, 1898. BY WILLIAM N. SWIFT, M.D.,

NEW BEDFORD, MASS.

Mrs. L. R., aged 21 years, married two months. Probable gonorrhea two years before; since that time, more or less pelvic pain and very marked pain at menstrual periods. Since marriage has had great pain across lower part of abdomen. Coitus so painful that it became impossible. Examination showed uterus much enlarged, very sensitive, retroflexed and somewhat toward the left side. Enlarged tubes felt on both sides. Operation, Aug. 9, 1897.

The bladder was separated from the uterus without difficulty. Plica opened with scissors. Extensive adhesions over the fundus of uterus and tubes. The uterus was seized with double hooks and delivered through the wound with some difficulty. The left tube and ovary were firmly adherent. The tube was freed from adhesions and on being opened was found to be entirely disorganized and occluded. It was removed, but the ovary was left as it was-normal. The right ovary and tube were bound down by strong adhesions. The ovary contained one large and many small cysts. On section, it showed no normal tissue. The tube was also much thickened, and both ovary and tube were removed. The uterus was fixed by three silkworm gut sutures through the vagina, peritoneum and uterus itself, then peritoneum and vagina on the other side. After these sutures were put in place, the peritoneum was sewed up with a continuous catgut suture, and later the wound in the vagina. After coming out of ether, the patient showed no symptom of shock. She passed urine on the morning of the second day. Examination at present shows no tenderness over scar in the vagina. Uterus small, in normal position, not tender. Some tenderness over left ovary, which can be plainly felt. Patient feels well and has worked since two months after operation. Coitus has not been painful. Has menstruated regularly, with only at times slight pain over region of left ovary.

There are several points in this case that are interesting: First, the question of abdominal or vaginal section in such a case. The chief advantage of the vaginal route is that it is a much less serious operation than abdominal section. There is no abdominal scar with risk of hernia. The patient has much less discomfort and pain immediately after operation. She can turn on her side at once and is usually up in two weeks. Another great advantage in vaginal section is the ease with which any operation can be done on the uterus, tubes or ovaries, after they are delivered. A small vagina makes the operation difficult even with lateral incisions. A fixed uterus that can not be drawn down at all makes the operation impossible.

The method of opening the peritoneal cavity which I employ is practically the one described and practiced by Professor Duhrssen of Berlin. The parts are made as aseptic as possible. The cervix is then dilated, curetted with a sharp curette, afterward with a douche-curette, and washed out with corrosive-sublimate solution (1 to 10000). The anterior lip of the cervix is then seized with the fixature. This instrument, as used by Prof. A. Martin, consists of a stout sound behind and a pair of stout double right-angle hooks in front, set on a broad surface. The sound is inserted into the uterine canal, the double hooks into the anterior lip of the cervix, which is compressed between the two. The uterus is then brought down as far as possible and held forward. An incision about half an inch long is then made through the vaginal mucous membrane at the upper border of the anterior lip of the cervix. One must be careful not to make this incision too high up, for in pulling down the uterus the bladder is displaced and may be wounded. This incision is prolonged with scissors about half an inch on each side. A double tenaculum is put on the vaginal mucous membrane at the center of the incision, and traction made upward. The bladder is then separated from the uterus by the finger, aided at times by the closed points of the scissors.

It is important to carry the dissection well out on each side so as to have the ureters as well as the bladder out of the way. By keeping close to the uterus there is no danger of wounding the bladder. This dissection is carried as far as the internal os. It is a mistake to strip off the peritoneum from the uterus farther up than this point. The fold in the peritoneum may be felt by the finger against the anterior surface of the uterus, and in most cases may be seized between the thumb and finger. An artery clasp is then put on the peritoneum and the peritoneal cavity opened by a small snip with the scissors, as near the uterus as possible. Artery clasps are then put on each side of the opening in the peritoneum and the bladder dissected away from the peritoneum still farther. As the bladder is pushed away, the peritoneum is slit up and clamps put on each side as guides. A pair of double hooks are put on the vaginal mucous membrane about half an inch below the urethra. The middle point of the vaginal mucous membrane in the transverse incision is seized with forceps. Traction is made with both instruments and the ridge made in the mucous membrane is slit up with scissors. The triangular flaps of vaginal mucous membrane formed by the transverse and longitudinal incisions are then dissected away from the bladder. This usually peels off easily with the shut points of the scissors. If vaginal fixation is to be done, the sutures are then inserted on each side through vaginal mucous membrane and peritoneum. I began by using silkworm gut, but since my first two cases have used catgut, the silkworm being rather troublesome to remove. This incision gives a wound extending from the cervix to the urethra, and laterally about an inch on each side of the cervix.

The examination of the uterus and adnexa is next 